\title{
Content valuation strategies for digital subscription platforms
}

\author{
Raoul Kübler $^{1} \cdot$ Rouven Seifert ${ }^{2} \cdot$ Michael Kandziora $^{2}$
}

Received: 30 January 2019 / Accepted: 31 August 2020 / Published online: 17 September 2020

(c) The Author(s) 2020, corrected publication 2021

\begin{abstract}
For digital video subscription platforms, creating and managing content portfolios are critical to acquire new customers, retain existing customers, leverage cross-sales, and generate advertising revenues. We treat content portfolios as a form of pure bundling which may vary in composition and attractiveness over time. Therefore, evaluating the value contribution of each content piece is essential to manage a platform's portfolio efficiently and to understand how a specific content piece contributes to the bundle's attractiveness. In this article, we develop an ROI content valuation framework for a digital film subscription platform. This framework describes how a single piece of content diffuses through consumers' journeys and influences subscription fees through acquisition and retention as well as revenues from cross-sales and advertising. This conceptual approach allows us to address the heterogeneity across content and platform contingencies such as exclusive availability and platform specifics, and link them to revenue streams. Building on this framework, we offer avenues for future research and provide potential lead performance indicators together with their operationalization, enabling all parties involved in the production, marketing, distribution, and sales of content to determine the platform-specific value of a content piece.
\end{abstract}

Keywords Video on demand · Business models · Content strategy · Portfolio valuation

JEL Classification L82 $\cdot$ M21 · M30 - M31

Raoul Kübler

raoul.kuebler@uni-muenster.de

Extended author information available on the last page of the article 


\section{Introduction}

Digitization has fundamentally disrupted how audiovisual content is produced, distributed, and consumed. This technological development has culminated in a vast array of digital video subscription platforms (DSPs) such as Netflix, Amazon Prime, and Hulu absorbing a majority stake in movie consumption (Deloitte 2018; PwC 2019). In 2018, Netflix (2019) alone generated $\$ 15.79$ billion in worldwide revenues, with the USA and Canada contributing $\$ 8.28$ billion. In the USA alone, 55\% of homes spent more than $\$ 2$ billion a month on streaming entertainment for the more than 200 video-on-demand services available (Wang 2018).

We take as our focus DSPs in which consumers pay a specific fee to access a pool of audiovisual content. This DSP market has witnessed substantial growth in the last decade, with its major players-Netflix and Amazon Prime-not only dominating the online video-on-demand landscape (Statista 2019) but also affecting other parts of audiovisual entertainment. According to Hennig-Thurau et al. (2019), German consumers spend more time with Netflix than with any single TV station, and even Hollywood studios such as Disney, Warner/AT\&T, and Universal have entered the streaming business. By 2023, streaming revenues are expected to represent roughly $75 \%$ of the revenues of the sequential audiovisual content cash flow chain, with a predicted market volume of $\$ 37.3$ bn (Statista 2019).

DSPs must provide content that inspires new customers to join, retains existing customers vital to the platform, and prevents users from switching to competitors or churning the service. However, determining content that satisfies these requirements and thus generates value for the DSP is challenging. Most platforms currently rely on rather simplistic approaches (Dastin 2018), such as monitoring the intensity per cost of newly acquired customers to calculate acquisition content value. However, they ignore indirect and difficult-to-observe effects that have been shown in nonentertainment industries to lead to income losses of more than $20 \%$ due to misallocation of marketing budgets and erroneous portfolio decisions (De Haan et al. 2016; Kannan et al. 2016). Content valuation becomes even more challenging given consumers' transition from passive consumption (e.g., of TV broadcasting) to active, individualized, and diversified behavior (Hennig-Thurau et al. 2019; PwC 2019).

The substantial growth of the market has attracted more competitors that try to conquer market share with the help of aggressive pricing and bundling (e.g., Disney + with Hulu, ESPN +) or third-party content integration (e.g., Amazon channels) (Sherman 2019a). In this increasingly competitive environment, platforms try to secure or protect market share by investing in content, as underscored by intensely discussed investments such as the US\$100 m exclusive one-year acquisition of the TV show Friends by Netflix (Lee 2018) or the US\$250 m Lord of the Rings deal of Amazon (Sherman 2019b). Such fundamental initial investments in a market with fluctuating consumer preferences for a holistic product pose substantive corporate risk-as experienced by managers enduring multiple box office bombs every year (Clark 2019). Given the high risks involved and the high investments necessary, being able to value content and its impact on platform revenues becomes even more essential. 
However, the question of how to determine the value of content is, at best, underdeveloped. So far, the economic literature on bundling has shown that digital home entertainment distribution is especially suited for bundling (Geng et al. 2005; Stigler 1963). The marketing literature provides different general return-on-investment (ROI) valuation frameworks (Rust et al. 2004) for products and services. In addition, research has expended substantial effort to understand the success factors of movies and TV shows at the box office and in home video distribution (e.g., Danaher et al. 2010; Eliashberg et al. 2006; Ravid 1999). However, no research has accounted for the particularities (i.e., relying on flat rates rather than valuating single content pieces or the dynamic interaction of revenues from subscriptions, advertising, and cross-sales over time) of the DSP market. Therefore, in this article, we develop a conceptual framework that enables all parties involved in the production, marketing, distribution, and sales of content to determine the incremental value contribution of a content piece and its value drivers. Our model should therefore be helpful for producers, distributors, and platform managers to properly assess the value of content for a DSP and thus enable all parties to fairly negotiate content transactions. Furthermore, our model can benefit future entertainment and cultural economics scholars who aim to model the film and media industry and its transaction processes. Overall, we are interested in two key questions: (1) How can the value of a content piece for a DSP be determined while accounting for direct and indirect cash flow contributions? and (2) How do content and platform contingencies moderate the relationship between content and value for a DSP?

In addressing these questions, we provide three contributions to the literature. First, we develop a framework for content valuation and relate content to the decision funnels of non-customers and acquired customers. This involves including an extensive set of possible performance indicators. For each factor, we recommend measures that can be applied to determine content value. Second, we investigate how specific content and platform contingencies influence the particular stages of the customer journey. Our conceptual framework is flexible with regard to a broad range of factors occurring at each stage. We explicitly discuss these factors, which are new and of substantial relevance. Third, we describe an extensive set of content and platform contingencies, derived from current industry practice, potential future industry trends, and related academic literature. Based on theoretical considerations, we postulate the impact of these contingencies and provide measures to capture them.

\section{Evolution of DSPs and their business models}

DSPs offer bundles of entertainment pieces to their customers for a fixed monthly or yearly price (Smith and Telang 2019). Consumers accessing the bundle can consume all elements of the bundle for the respective price. Such bundling business models are especially suitable for products with no or almost no marginal costs and customer bases with highly heterogeneous, decreasing, or unobservable preference and utility structures (Elberse 2010; Geng et al. 2005; Long 1984; Stigler 1963, 1968). Stremersch and Tellis (2002) provide an overview of different bundling 


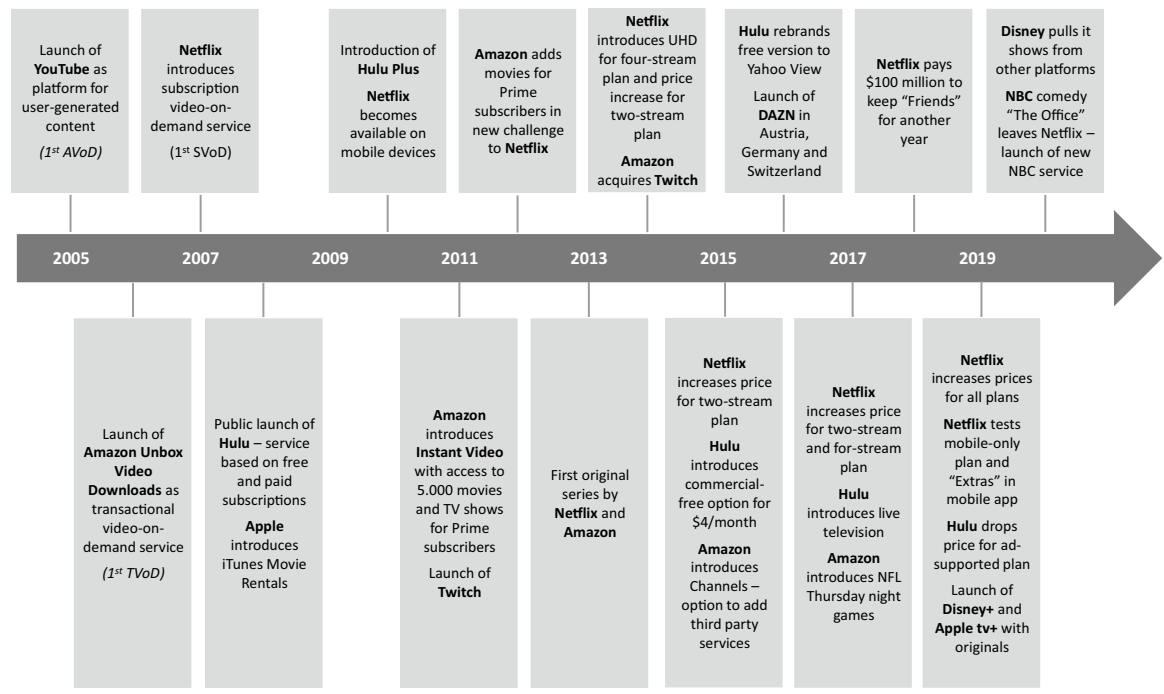

Fig. 1 Key events in the evolution of the market for digital platforms

strategies unifying the so-far often-inconsistent naming across the economic and marketing literature. They distinguish between price and product bundling as well as pure and mixed bundling; in pure bundling, consumers choose only between buying and not buying the bundle (e.g., subscribing to Netflix or not doing so). In mixed bundling, consumers select between buying a title separately physical (e.g., buying a single content piece as DVD/Blu-ray) or digital (purchase or rental via, e.g., Amazon, which refers to Transactional Video on Demand (TVOD) in the industry) and buying the whole bundle (e.g., by subscribing to Netflix, which refers to Subscription Video on Demand (SVOD) in the industry). In the following, we treat all SVOD activities as a form of pure bundling, in which consumers have the choice to subscribe to a whole bundle of different content pieces, which may vary in composition and attractiveness over time.

Since 2005, new platforms have been entering the video-on-demand market, with tech companies such as YouTube, Amazon, Netflix, and Apple shaping the first years of the industry, followed by the entry into the market of TV stations, infrastructure providers, and, more recently, traditional content producers such as Disney. We depict the evolution and major events during the last 15 years in Fig. 1. In addition, Table 1 provides a detailed description of the specific business models of the key DSP players along with a description of the current status quo of the DSP market. Regarding the general business model, a shift has occurred from TVOD (digital purchase and rental) to SVOD consumption as in the case of Amazon Prime Video, for example. In addition, new entrants such as Disney + and Apple TV + mostly follow the SVOD approach. An increasing number of companies have also implemented cross-sales and subscriptions from affiliated online shops (Sherman 2019b) or generated advertising revenues from commercials (referred to Advertised Video on Demand (AVOD) in the industry) as additional revenue streams. 


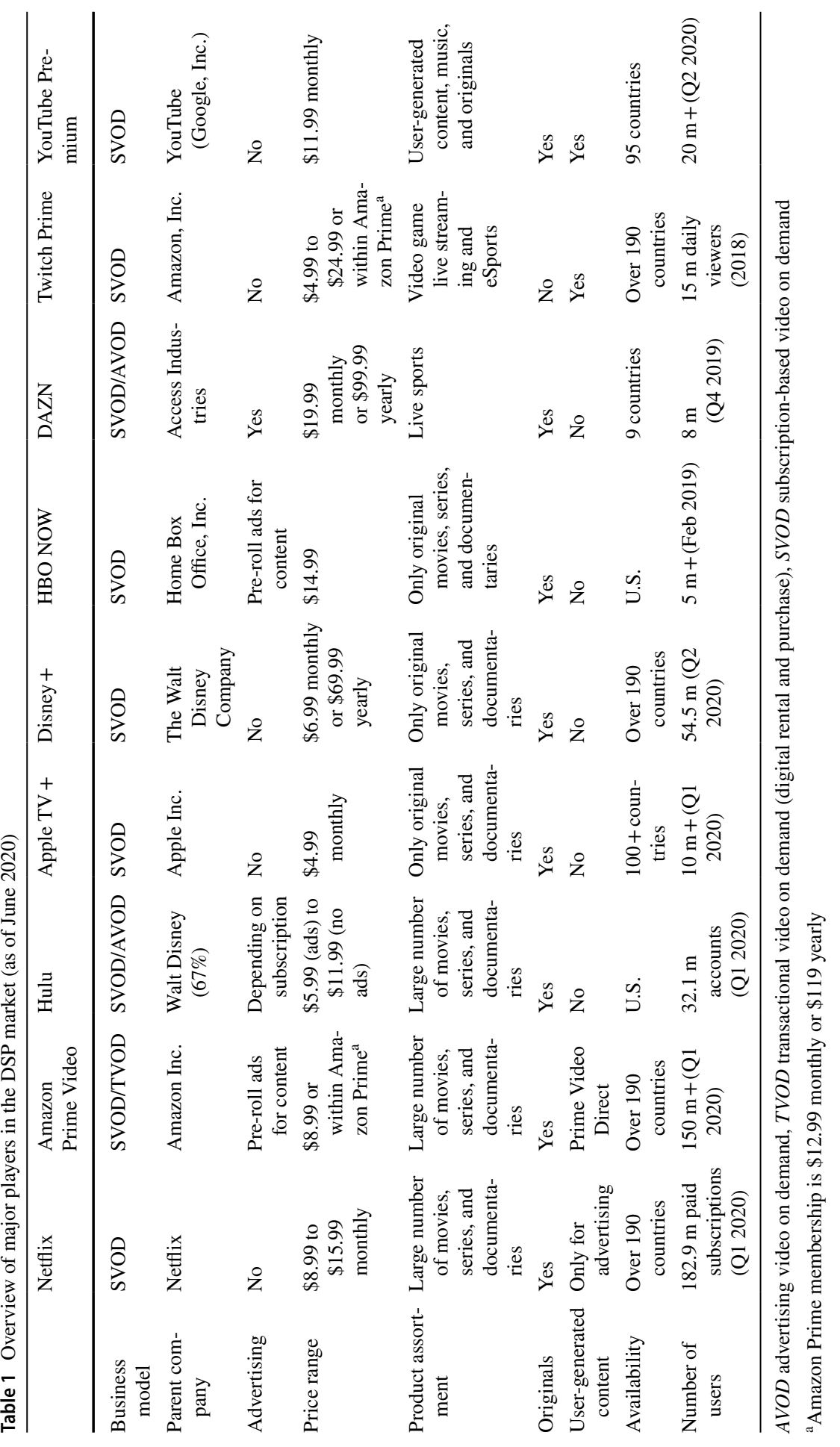


All DSPs on the market rely on up to three different revenue streams in combination, with platforms following different strategies. The majority of DSPs (e.g., Netflix, Disney +) generate a large proportion of their revenues from consumers who pay a regular subscription fee to access a pool of content for a specified period. Other platforms add revenues through cross-sales (e.g., Amazon, Apple) or advertising (e.g., YouTube, Hulu). Of note, while most players generate revenues primarily through their streaming services, Amazon and Apple, in particular, accrue a major share of their revenues from other lines of business, which is likely to influence their content strategy as well. To ensure constant revenues from subscription fees, the two most important processes for platforms are the acquisition of new customers (noncustomers) and the retention of existing customers. As the acquisition of new customers can be rather expensive (Wertz 2018), platforms also need to focus on retaining their customers. For example, DSPs periodically introduce big new releases to try to prevent customer churn. In addition, Netflix has gradually shifted from movies to TV shows (Clark 2018) as it attempts to increase the activity level and lock in customers. Furthermore, a higher activity level might create value by affecting cross-sales and advertising. However, regarding the status of consumers, it might be simplistic to differentiate only between customers and non-customers, as consumers might follow a more complex decision process. For example, media and online buzz caused by the introduction of House of Cards (Morris 2016) helped Netflix raise awareness of the platform substantially. While this may have resulted in some consumers signing up for the service and changing their status from non-customer to customer, others may have only joined later, when Netflix created other content (e.g., Orange Is the New Black). However, the release of House of Cards might still have increased the probability of their acquisition.

Starting in 2014 and continuing to today, streaming platforms have constantly been making minor adjustments to their business models, mostly to pricing, streaming quality, and commercials. For example, while Netflix increased prices several times but has no commercial breaks, Hulu introduced a commercial-free option for \$4 per month in 2015 and dropped the price for the ad-supported plan in 2019.

With respect to content and platform assortment, Netflix, Amazon Prime Video, and Hulu rely on a relatively broad array of offerings with a large number of movies, series, and documentaries that include licensed content, while Apple TV +, Disney + , and HBO NOW only offer original content. YouTube and Twitch primarily rely on a third option to source content-namely user-generated content. As licensing costs are increasing and content producers such as Disney or NBC begin pulling their content from other DSPs (Goldberg 2019; Raghunath 2019), companies such as Netflix and Amazon are increasing their investment in in-house productions (Spangler 2019), attempting to reduce their dependence on licensing third-party content and enable exclusive offerings. Furthermore, in-house productions allow companies to make use of user data to target the tastes of their customers specifically. Thus, with new services being added all the time and the subsequent increase in competition, the content strategy of video-on-demand service providers plays a pivotal role in their success. Therefore, the constitution of the assortment in terms of size, topicality, and diversification plays a major role for the business model of subscription services. While some services such as Netflix and Amazon offer a 
broad catalog with different genres, DAZN is focused on live sporting events. Thus, streaming platforms also compete in their assortments and have begun adding live content and third-party channels to their catalogs as, for example, Amazon has done with Amazon Channels. All these different business models with heterogeneous content strategies aim to create a competitive advantage in the DSP market.

\section{A content valuation framework}

In this section, we discuss five challenges to the value measurement of audiovisual content for DSPs. In considering these challenges, we formulate our content valuation framework. As a starting point and theoretical underpinning, we discuss the bundling literature that provides different applications in which bundling exceeds the distribution of a single (unbundled) product or service.

The early majority of bundling studies focused on the suitability of bundling and the factors that determine whether products should be offered separately or in form of a mixed or pure bundle (e.g., Danaher et al. 2014). This stream of research concludes that bundling strategies are especially suitable when products have little or no marginal costs (Stigler 1963). Furthermore, bundling becomes more attractive when consumer utilities $^{1}$ (also referred to as the product's value to an individual customer in the economic literature) for all elements of a bundle are difficult to observe (Fang and Norman 2003) and slowly decrease along the bundle package (Geng, Stinchcombe, and Whinston 2005). While early economic research on bundling examined the effect of bundling in monopolistic (Adams and Yellen 1976; Armstrong 1996; McAfee et al. 1989) and duopolistic (Armstrong and Vickers 2010; Zhou 2017) markets, more recent research finds that bundling can help prevent competitors from entering markets (Nalebuff 2004). In addition, marketing research on pricing bundles has shown that bundling can be especially suitable for digitally distributed goods (Danaher et al. 2014) and information and entertainment goods (Geng et al. 2005).

While the majority of bundling research focuses on the decision of whether to offer products separately or in the form of a bundle, only a few studies examine the valuation of bundles. This sub-stream of the bundling literature, however, mainly focuses on the question of how to price the whole bundle by assessing the total attractiveness of a bundle for a given customer base. Such a perspective of bundle valuation is certainly helpful in case of a single purchase or acquisition of consumer goods, where consumers need to only think once whether to buy the bundle or the product separately. However, an overall pricing value measurement approach seems less helpful in a scenario in which (1) the bundle content dynamically changes and (2) bundle prices need to remain constant over time, and (3) consumers periodically decide whether to stay with the bundle or not as in the case of DSPs. In addition, the majority of the bundling literature only accounts for one-time adoption, while in the

\footnotetext{
1 We use the term "consumer utility" here to avoid any confusion with our own value term, which captures the profit contribution of a content piece to a DSP's total profit.
} 
case of SVOD platforms, revenue streams originate not only from new customers but also from retaining customers. Furthermore, prior studies offer only very limited insights on the impact of adding a new content piece to the bundle on cross-sales and advertising metrics. Therefore, the bundling literature is especially helpful when it comes to the questions whether to generally offer movies in the form of a bundle (producers, platform owners) and what kind of bundling approach (i.e., mixed or pure) to choose. Existing insights might therefore guide decisions of platforms such as Amazon Prime and Disney + on whether to include a content piece solely on the platform (pure bundling) or also offer the piece in addition to the DSP as, for example, a digital download or Blu-ray and DVD (mixed bundling).

Our framework, however, takes the perspective of a manager (e.g., of a content producer, content distributor, channel operator) who already decided to add the content piece to a bundle and who now needs to understand how the specific piece contributes to the bundle's attractiveness to determine how much to pay for the piece (distributor or DSP manager) or how much to ask for the respective piece (producer). We first highlight the challenges arising from such a task and then identify and discuss content- and platform-specific contingencies that determine the value contribution of a single content piece to the platform's revenue streams.

\subsection{Challenges of value measurement}

The literature provides various general brand or customer-centered valuation frameworks (see Berger and Nasr 1998; Keller 1993; Venkatesan and Kumar 2004); however, these do not account for the specific particularities of the DSP market. We aim to develop an ROI framework that takes the perspective of a DSP and is able to assess the value of a specific content piece, such as a movie or series, in the context of a specific DSP. Before doing so, we first discuss in detail different challenges a DSP faces in trying to determine content value.

We define content value as the total value contribution of a content piece generated through cash flow on a certain DSP. However, as we noted in our description of the development of the DSP market, cash flow streams vary greatly across platforms as a result of multiple revenue streams and revenue strategies; therefore, a content valuation framework needs to be able to address the multitude of streams, which leads to our first challenge:

Challenge 1: Multiple revenue streams. DSPs generate their revenues from combining up to three revenue streams: subscription fees through acquisition and retention, cross-sales, and ad revenues. A content-valuation framework thus needs to be able to not only account for these particularities but also measure how a content piece affects each revenue stream separately.

Next and not limited to different revenue streams, platforms are not homogeneous. The ecosystem of each DSP is characterized by different contingencies, such as assortment, subscription plans, and business models. These contingencies are related to the platform, customer preferences, and the competitive environment and affect the relationship between content and the acquisition and retention 
processes. In line with the classic bundling literature, for example, the addition of The Hobbit trilogy may have a different impact on platform engagement, customer retention, and the acquisition potential for a platform that already owns The Lord of the Rings trilogy than for a platform that has no related content, as the utility generated by a newly added piece is positively correlated with the utility of the existing content piece (Geng et al. 2005). This leads to our second challenge:

Challenge 2: Platform heterogeneity and resulting contingencies. A valuation framework also needs to be able to account for platform-specific heterogeneity and incorporate these contingencies into the valuation process.

Accordingly, to measure the value of an existing content piece, buyers and sellers of content may associate any variance in one of the cash flow streams with the presence or absence of the particular content piece. However, this rather simple approach only accounts for the direct impact of a content piece on different revenue streams while ignoring other indirect effects that may occur (e.g., increase in DSP brand awareness). For example, assume that by introducing House of Cards, Netflix directly stimulated 1000 customers to subscribe to its service. At the same time, House of Cards similarly increased public attention to the platform and may have altered the general awareness or consideration of Netflix as an online streaming service for other consumers. These consumers, having heard of Netflix for the first time from the introduction of House of Cards, may then later join the platform when other content becomes available, such as Orange Is the New Black (the second most successful show on Netflix). This scenario leads to the third challenge for content value measurement in the context of a DSP:

Challenge 3: Direct and indirect value contribution. A consumer's decision on whether to join a platform and engage with its content follows an elaborated choice process related to the customer journey; therefore, a content-valuation framework needs to account not only for the individual contribution of a content piece on each of the DSP's own aggregated mindset metrics on the path from awareness to satisfaction but also for the indirect effects along the customer journey.

The consumer's decision making does not follow a straightforward process; rather, it follows a decision funnel (Srinivasan et al. 2016) that goes through different stages and iterations (Edelman and Banfi 2014), multiple types of carryover effects (e.g., from awareness to consideration to purchase), and lagged effects across the decision process with, for example, one piece increasing awareness (i.e., House of Cards) and another piece inducing subscription (i.e., Orange Is the New Black). This leads to the fourth challenge:

Challenge 4: Dynamic and time-varying effects. A content-valuation framework needs to be able to account for time-varying effects and to incorporate the whole path from attribution to performance (metrics), as well as the dynamics within this process (e.g., lagged advertising effects), along the customer journey. 
So far, the measurement of value has been restricted to the measurement of a specific content piece's direct and indirect cash flow contribution to a platform. This approach makes it possible to determine the value of existing content but not to make predictions for not-yet-existing content. To be able to make decisions on what type of content to acquire, license, or produce, DSP managers need to be able to predict how a piece will contribute to the platform's revenue based on its individual characteristics. To achieve this, they must understand how the measured value of a content piece is related to the specific contingencies of the content. In statistical terms, this means that they must explain the variance of content value from the variance of content contingencies, which leads to our fifth challenge:

Challenge 5: Content heterogeneity. From an economic perspective, content (e.g., a movie) is a bundle of contingencies (e.g., genre) assigned to a specific piece. As noted previously, this makes it likely that different content contingencies will affect the three revenue streams differently (see Challenge 1), as different contingencies have differing potential to affect the different stages of decision making (Challenge 2) at different times (Challenge 3). To be able to predict the value of newly created content, a content-value framework needs to be able to not only predict value on an aggregated content level but also estimate the value as a result of the heterogeneous combination of content contingencies by accounting for the impact of each contingency on the customer journey and revenue streams, dynamically and over time.

\subsection{Framework}

Figure 2 gives an overview of our content valuation framework for DSPs. The framework describes how a single piece of content contributes to a platform's total cash flow by influencing customers' acquisition and retention processes, yielding the overall content value generated during both processes. The overall content value is calculated as the sum of value generated from each revenue stream. Again, the three streams are subscription revenues through acquisition or retention, cross-sales, and advertising revenues. Starting with a piece of content such as a movie, a series, or a live event, each content piece consists of different content and platform contingencies. Each contingency might have an impact on both the acquisition and retention process, but each relates to at least one.

To account for the direct and indirect value contributions of a content piece as well as for the dynamics involved in indirect value contributions, we follow mainstream ROI literature in marketing (e.g., Farris et al. 2015; Srinivasan and Hanssens 2009) and decompose the potential impact of content during both processes into attributional and performance metrics. Thus, we not only gain a more elaborate view of the value creation chain leading to the three revenue streams but also are able to plan and forecast the cash flow in relation to the platform portfolio.

With regard to the acquisition process, the consumer's journey starts with the acquisition funnel, which leads to the acquisition decision and initial post-acquisition behavior (e.g., a first content choice). The DSP receives periodical fees 


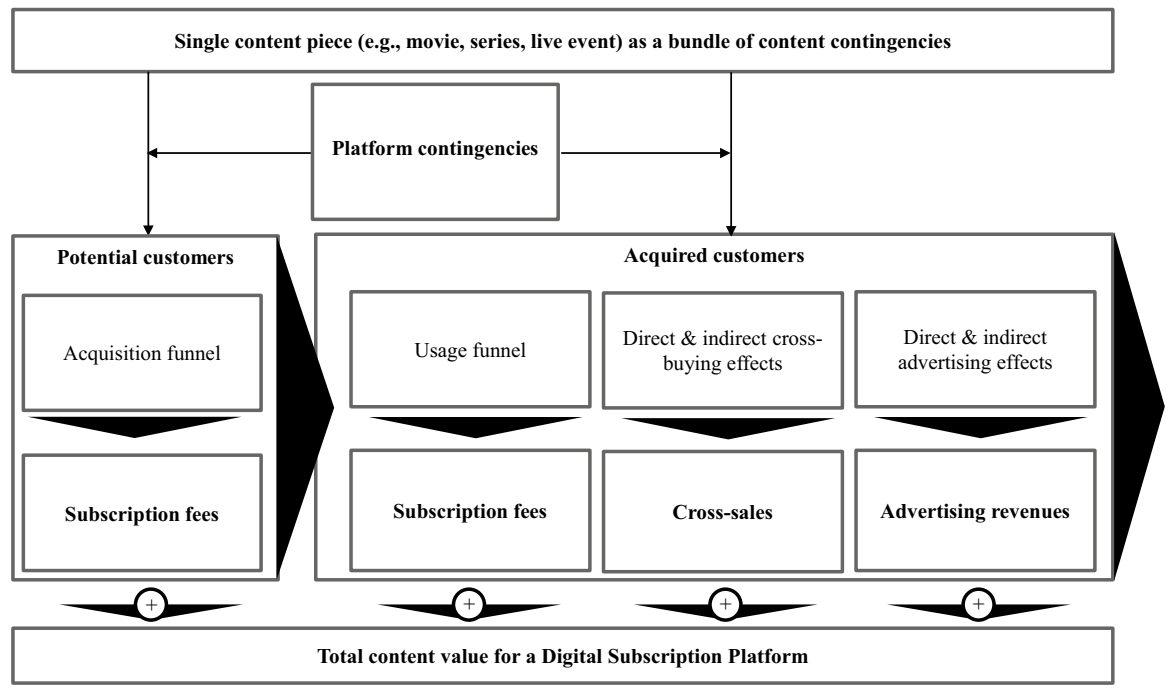

Fig. 2 Conceptual framework

from each acquisition. A content piece may directly generate acquisition revenues or affect any mindset metric leading to an acquisition.

As long as a consumer is loyal to the service, the DSP generates periodical fees from each customer. In the case of commercials, the customer is confronted with consumption interruptions, which form an advertising experience. The DSP also generates advertising revenues from each advertisement shown. Furthermore, different DSP business models include cross-buying opportunities that lead to crosssales resulting either from direct interactions with a specific content piece franchise or through stronger platform engagement or platform loyalty.

As described in Sect. 2, the market for DSPs is differentiated into different customer segments. First, many DSPs compete for customers' favor with different business models and product assortments. Each content piece is affected by platform contingencies, and they are grouped into those related to the platform, the competition, and customer preferences. These platform contingencies interact with the content contingencies: the greater the fit between both types of contingencies, the more value is generated from the content. Second, DSPs are heavily dependent on their customers. The ecosystem and cultural background of customers are quite relevant for the value of a content piece, as indicated by the cultural challenges Netflix faced when launching service in France (Hall 2014). Finally, strong competition might also affect the value of a content piece. According to Netflix's (2019) annual report of 2018, not only direct competition but also adjacent industries, such as the gaming industry, affect the time budget customers have to spend on leisure activities. Moreover, both the allocation of time budgets to certain leisure activities and the total amount of time are subject to change given the convergence of media. 


\section{Determining the incremental value of content}

To measure the value of a content piece or its particular contingencies under certain platform contingencies, we rely on the concepts of customer experience and customer journey (Lemon and Verhoef 2016) and combine them into a classic marketing effectiveness measurement model that accounts for the impact and dynamics of adding a content piece to different stages of the journey. For each stage, we suggest multiple performance indicators that capture the "customer's cognitive, emotional, behavioral, sensorial, and social responses to a firm's offerings" (Lemon and Verhoef 2016, p. 74) during the customer's journey. Each performance indicator focuses on a distinct touchpoint of the dynamic experience process and can be operationalized by different measures to address the direct and indirect value contribution to a platform's cash flow, as depicted in Table 2. Thus, we have a dynamic framework with three levels that help measure the impact of a content piece on each of the metrics and also the impact of each of the potential performance indicators not only on each other but on the final outcome variables as well (i.e., cash flow in each of the three revenue streams). As such, we account for both the direct effect of the content piece on the particular revenue stream and the indirect effects along the customer journey to join a platform (acquisition) and stay with the platform (retention).

\subsection{Acquisition}

Need recognition is followed by information search and then information evaluation, which helps the consumer form a consideration set and finally becomes the focal point of decision making, leading to the final choice (Hanssens et al. 2014; Hauser and Wernerfelt 1990; Kannan et al. 2016). Users' awareness of a specific platform may be heightened by the introduction of a specific content piece. Although a user might not immediately join the platform, this content piece is valuable as it is the starting point of this specific consumer's acquisition funnel to subscription. Similarly, other content pieces may increase this non-customer's level of interest or consideration without immediately converting him or her to a customer, thereby providing value from their contribution to the funnel and advancing the consumer in the funnel (i.e., lagged advertising effects; Conchar et al. 2005).

Proper value measurement, therefore, needs to account for pre-purchase funnel stages, such as awareness and consideration, and also needs to measure their impact on the consumer's final decision to register for a platform (Wiesel et al. 2011). Consumers may have been exposed to other advertisements or other content pieces, which may have built up some sort of awareness and consideration stock; this stock fosters a certain likelihood of the consumer finally clicking on an advertisement and, only then, purchasing a product (Hanssens et al. 2014). DSP awareness may be successfully measured with the help of classic survey-based metrics, as well as with social media content or user-generated content related to the platform (Kübler et al. 2020). To track platform awareness and platform brand strength, managers may on the one hand use key performance indicators (KPIs), such as brand equity measures provided by marketing research companies such as Nielsen, YouGov, or GfK, but 


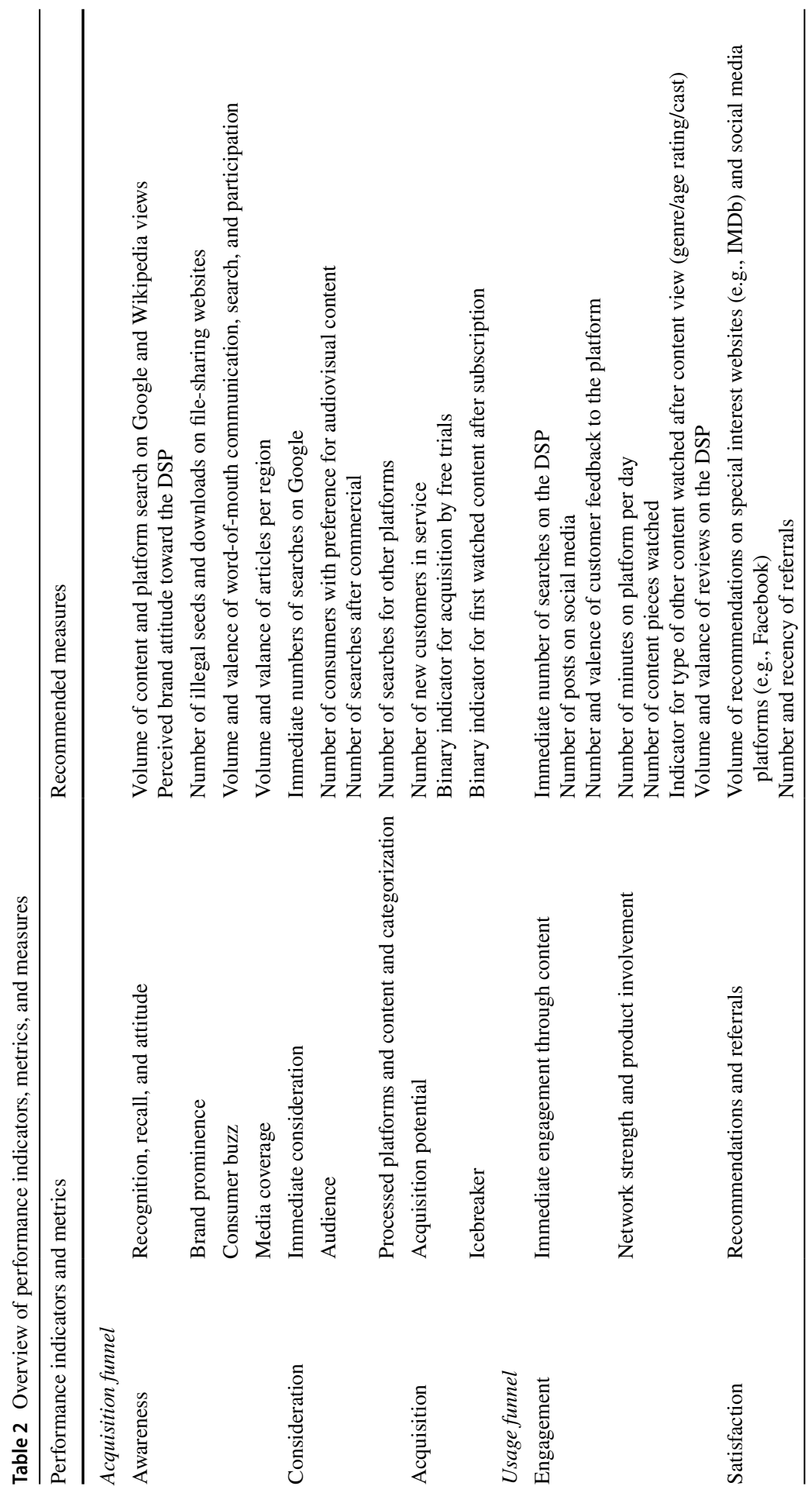




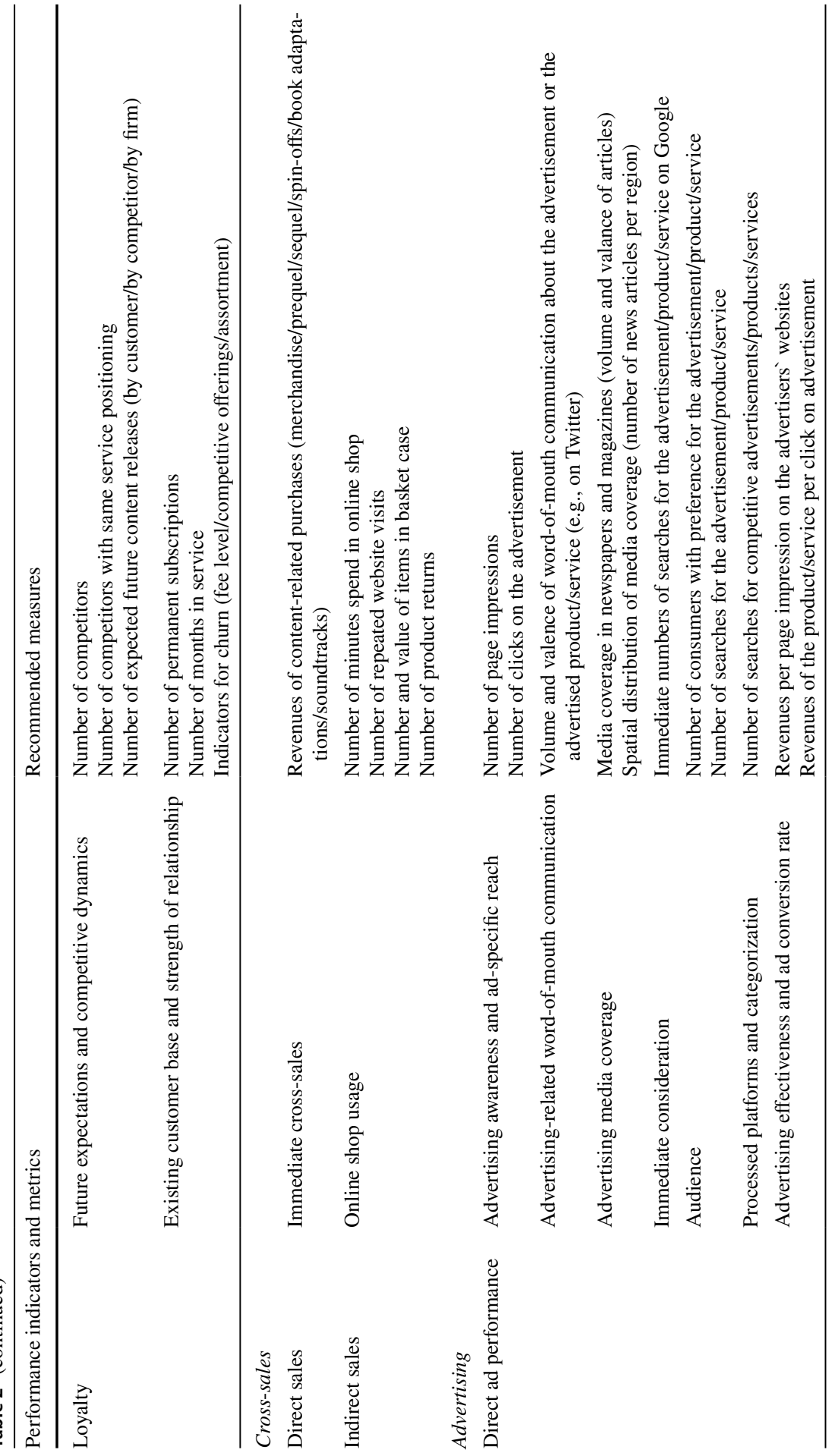




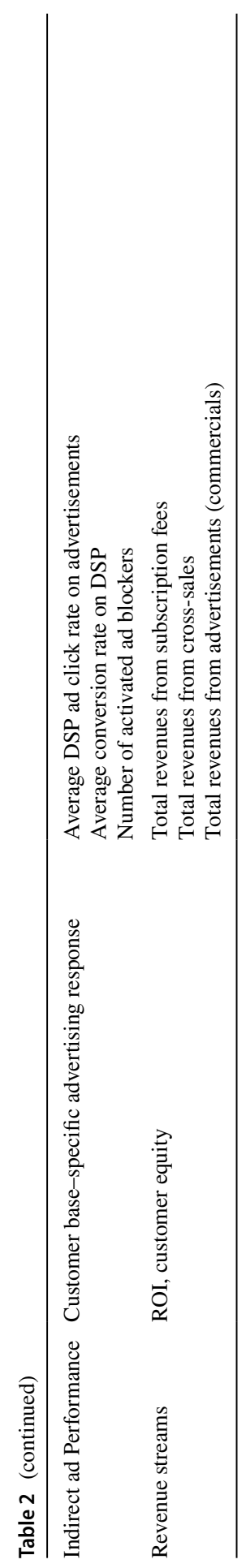


on the other hand may also rely on user-generated content, such as the web searches for the platform or content piece, streaming searches from affiliate pages, or social media mentions of the platform. Furthermore, we recommend to rely on the level of press or online coverage of the platform to measure brand strength and brand awareness and to assess how these values change from the addition or removal of a specific content piece. Similarly, managers may control how the presence of a content piece changes lower elements of the decision journey, such as by monitoring consideration with classic survey-based metrics, in which representative consumers are continuously and directly asked if they are considering joining a platform, or by continuously monitoring consumer preferences through, for example, choice experiments, which explore an average consumer's consideration set. A last option to track consideration is to examine search behavior across a platform by analyzing search term relationships, as provided by Google search. Table 2 features other possible variables that can be tracked to measure platform consideration and to relate the inclusion of a content piece to changes in any of these variables.

\subsection{Usage}

Content may further provide value by keeping customers engaged and prevent them from churning. Ongoing consumer engagement with a platform is likely an outcome of customer satisfaction. The more satisfied a customer is, the less likely he or she will be to churn (satisfaction scales; e.g., Churchill and Surprenant 1982; Fornell 1992; Peterson and Wilson 1992). Especially with bundled services, we can assume that consumers stay with the service providers as long as the total utility gained from the bundle is greater than the utility from acquiring single pieces separately. Platform engagement may thus be a good indicator that utility a consumer receives from the platform is high enough to keep him or her from churning. Engagement can thus be measured as the average time per user on a platform. However, instead of measuring engagement or platform activity levels, buyers and sellers of content may evaluate how many customers are inactive and how inactivity changes or is interrupted by the presence of a specific content piece (or by specific characteristics of content pieces). Shorter periods between accessing similar pieces of content—as in the case of binge-watching - may reflect stronger platform engagement and satisfaction potential. Furthermore, a movie's ability to reengage inactive customers can be used as a potential performance indicator. We therefore recommend measuring the retention contribution by analyzing how the presence of a content piece is related to measures such as the average time spent on a platform, the average number of pieces consumed on the platform, the number of searches in the platform, or the average inactive time between the consumption of two pieces.

The contribution to platform satisfaction can also be tracked either directly by observing how customer surveys using established scales (e.g., Net Promoter Score) change with the presence of a content piece or indirectly by measuring, for example, platform reviews or sentiment-based online word-of-mouth measures. Table 2 again provides a detailed list of possible measures and KPIs for retention and satisfaction. 


\subsection{Cross-sales}

A content piece may directly increase interest in a specific franchise (e.g., buying the sequel to Harry Potter after watching it) through related product categories (e.g., books) or even unrelated offerings (e.g., Lego City toys). Uncovering these relationships is, however, a more complex task that may be mastered with the help of classic basket or affinity analyses, which investigate the relationship between watching behavior and buying behavior on a platform and relate changes in the latter to the presence of a content piece. As Table 2 indicates, cross-sales-related KPIs for a content piece may include measures such as the average time spent on the cross-sales platform, the cross-sales platform's average basket size, the number of daily orders, the average amount spent, and the profit per transaction.

\subsection{Advertising}

Apart from generating direct revenues, a content piece may further contribute to the general acceptance of ads on a platform or may even increase users' interest in advertisements through ad effectiveness and ad efficiency, respectively. By providing suitable, interesting, and engaging content, a platform may make users generally more forgiving of ad interruptions, which may then be measured by tracking KPIs such as the platform's average ad click and ad conversion rates. Table 2 provides more advertising-related KPIs.

\section{Content and platform contingencies}

While the aforementioned performance indicators and measures are especially suitable for any sort of longitudinal or cross-sectional regression model that measures post hoc the impact of the addition of a content piece on one or multiple revenue streams, these variables hardly allow predicting how a platform's revenue will change with the addition of a specifically designed content piece. To be able to make such predictions - and to enable platform and content owners to negotiate fairlybuyers and sellers of content must also understand how content and platform contingencies as well as the interaction between platform and content characteristics influence the magnitude of the direct and indirect value contribution effects along the customer journey and revenue streams. In the following sub-sections, we therefore discuss content and platform contingencies, in which researchers as well as producers, platform managers, and distributors should consider including in their measurement models. These factors may act as explanatory variables or even as moderators to account for content and platform heterogeneity and to allow platform- or content-specific predictions. For the purposes of explaining content value variance and potential impact on KPIs, we rely on different theoretical considerations and prior research. 


\subsection{Impact of content contingencies}

We cluster the content contingencies into the four groups of content type, sourcing mode, content communication and social appeal, and life cycle and exclusiveness. Table 3 provides an overview of these four dimensions, their constructs, and recommended concrete measures in the DSP context. Prior studies, especially in the research field of entertainment, have documented various content and platform contingencies that affect the general success of content (for an overview, see Hadida 2009; Hennig-Thurau and Houston 2018). These studies carve out the links between these contingencies and performance metrics, predominantly box office success. Furthermore, they identify different moderating effects between contingencies (e.g., advertising and price; Gong et al. 2015). However, digital subscription channels differ from the other distribution options, and thus, the value contribution might differ from what is known from previous studies. In addition, DSPs raise novel phenomena that are intended to have a substantial impact on the DSP business model and that have not been investigated in the past.

\subsubsection{Content type}

DSPs must select among different types of content such as stand-alone movies, series, and live events. Each type of movie provides different ways of storytelling and features to target specific consumer segments. Especially series such as House of Cards initiated a revolution in storytelling, with creative innovations in narrative style, consumption schedule, and story length. Thus, value components that capture these story formats are important indicators in determining the value of content. In particular, series might have a positive association with loyalty (Payne and Frow 2005; Verhoef 2003; Winer 2001). This content type allows for the periodic release of new episodes, ensuring recurring activity and revisits on the user side, thereby resulting in customer lock-in. Movies and live events have also proved to engage many consumers. Story format can be measured through binary indicators that capture each type (Table 3 ). In addition, content includes different quality signals that enable consumers to reduce pre-consumption uncertainty. Prior research identifies various story characteristics, such as sequels, prequels, and remakes (e.g., Bohnenkamp et al. 2015; Hennig-Thurau Houston, and Heitjans 2009; Joshi and Mao 2012; Palia et al. 2008) that should be measured using binary indicators. The artistic quality of the director and cast determines the way the story is delivered to the audience, and star directors and actors induce a pull effect through their historical monetary success (e.g., Basuroy et al. 2003; Elberse 2007; John et al. 2017; Ravid 1999). While a typical measure of monetary star power is the historical cumulated revenues of the cast and director at the box office, a good proxy for artistic star power is the historical cumulated awards dedicated to the cast and director. Furthermore, content can induce forward and reciprocal spillovers to other pieces of content (e.g., HennigThurau et al. 2009). Especially series and recurring live events produce substantial spillovers. Another way to benefit from existing content is to produce spin-offs of 
Table 3 Overview of content contingencies, dimensions, and measures

\begin{tabular}{ll}
\hline Dimensions & Recommended measures \\
\hline
\end{tabular}

Contingency I: content type

Innovative storytelling and quality signals

Monetary and artistic star power

Forward and reciprocal spillover

Contingency II: sourcing mode

Resource base and creative control
Binary indicators for stand-alone movie, series, live event, and innovative forms of storytelling

Binary indicators for sequel, book adaptation, remake, and type of live event (concert/sports)

Genre and length of content in minutes

Box office history (total box office revenues) of the actors/director

Cumulated actors/director awareness score on special interest websites (e.g., IMDb)

Number of nominations and wins of awards for all actors/director

Genre-fit of the actors/director with content genre

Number of followers of the content creator

Number of historical content pieces by creator

Number of seasons and episodes

Recency of seasons and episodes

Number of views of episodes

Decrease in number of views

Number of spin-offs

Binary indicator for recurring live event

Total amount of external financial capital

Number of external investors

Volume and type of state funding

Binary indicator for user-generated content

Contingency III: content communication and appeal

Consumer communication

Volume and valence of microblogging

Volume and valence of forum posts (e.g., Twitter)

Differentiation by mass or niche audience

Rating of the person on social media

Type of person (company/private user/expert)

Number of posts

Platform of the posts

Search

Search volume (e.g., Google Trends and IMDb Moviemeter)

Differentiation by mass or niche audience

Participation

Volume and valence of postings and likes on social media platforms (e.g., Facebook)

Volume and valence of activities on special interest websites (e.g., Wikipedia)

Differentiation by mass or niche audience

Trends and ranking

Appearance and rank in consumer rankings Increase in number of posts on social media platforms per time period

Binary indicator for firestorm

Emotional and sentimental appeal
Binary indicator for evergreen

Sentimental profile of the plot (e.g., emotional words) 
Table 3 (continued)

Media coverage and publicity

Third-party signals of product quality (critics and awards)

Contingency IV: life cycle and exclusiveness

Sequential distribution through versioning, product, and price discrimination

Forward spillover

Degree of exclusiveness and scarcity of the content

popular movies or series. Aggregate sales and buzz metrics from preceding distribution channels can be used to capture these spillovers.

\subsubsection{Sourcing mode}

Typically, channel operators license their content from independent or major studios. However, research on product customization (e.g., Simonson 2005) and several DSP examples have shown that content optimized to the DSP's customer base can produce a substantial competitive advantage. According to the resource-based view (Wernerfelt 1984), no or only a few external investors keep creative control on the DSP, which increases capital costs that must be balanced. In addition, content produced in-house and distributed exclusively through the producer's own platform - such as Amazon or Netflix Originals - can increase a platform's reputation and its quality perception. Finally, the low production costs favor the integration of user-generated content but come with low creative control, which leads to the risk of undesired content (e.g., unethical content). Recommended metrics to measure the resource base and creative control are the number of external investors, the debt ratio, and binary indicators distinguishing between professional and 
non-professional content. Especially for user-generated content, content integration benefits from content creators' star power (e.g., social influencers) with high awareness. The number of followers and measures related to the network structure and the position of the creator in the network can capture social influences (Table 3).

\subsubsection{Content communication and appeal}

Communication theory and product and service research suggest that the DSP's performance depends on user perception (e.g., Liu 2006), media coverage and publicity (e.g., Rinallo and Basuroy 2009), and third-party evaluation by professional critics and awards (e.g., Basuroy et al. 2003; Gemser et al. 2008). The effectiveness depends on the volume and valance as well as social capital and identity of the sender of the message and its origin (e.g., the platform). Firm advertising and appearance in media outlets initiate content-related consumer buzz (Houston et al. 2018) to create awareness and desire for the content, which in turn culminates in substantial acquisition and retention potential, given consumers' associative link between the content and the DSP service. The distinct consumer buzz potential of a content piece depends on consumers' communication, search, and participation (Houston et al. 2018). The emotional and sentimental intensity of the story and staging further affect these constructs, given the hedonic nature of audiovisual consumption (Holbrook and Hirschman 1982). Entertainment products commonly show an exponential decrease in sales (Hofmann-Stölting et al. 2018). However, some movies may enjoy continuing attention and steady interest, as underscored by all-time classics such as the Star Wars franchise or Casablanca. Some cult content (e.g., Pulp Fiction) may further enhance attraction potential for both customers and non-customers over time. To capture volume, count variables are recommended. Valence, sentiment, and appeal can be measured through ratings.

\subsubsection{Life cycle and exclusiveness}

Typically, audiovisual products are sequentially distributed through different channels (Hennig-Thurau et al. 2007). Historically, DSPs achieve full exploitation after months or even years of distribution in theatrical and home video channels. However, DSPs expend substantial efforts in influencing the order of channels and the time span from initial release and DSP opening.

Especially through in-house productions, DSPs can optimize exploitation schedules using versioning, product and price discrimination, and exclusiveness to maximize their profits (e.g., Hennig-Thurau et al. 2007). The earlier in its own life cycle a content piece enters the platform, the more buzz and attention it may create, thus increasing awareness for the platform, which may lead to more new subscribers or may increase retention, as consumers expect the platform to include new titles earlier than others and, as such, may be more reluctant to stay with the platform without terminating the subscription or churning to a competitor. We therefore suggest including the time since home entertainment release (e.g., weeks) for each piece as a contingency factor. 
Another acquisition and retention effect may come from exclusive content pieces (Hamilton et al. 2019) that are available only through one platform and therefore may bring new customers to the platform or lock in the existing customer base. Amazon and Netflix Originals are prominent examples of combining exclusive distribution with in-house productions that are perceived as scarce, exclusive, and high quality and thus have strong acquisition and retention potential. Content valuation models may therefore include this scarcity effect by the number of days the piece is exclusively offered by the platform or whether other platforms also offer the same piece. However, by licensing in-house productions after the initial decline in attractiveness, the content may generate substantial revenues from distribution licenses to other DSPs and channels, as typically multiple distribution channels are required to break even. Hence, a subsequent release strategy for the content (e.g., after box office premiere) might be optimal, as subsequent channels experience buzz spillovers (e.g., Bruce et al. 2012) from preceding channels and creating consumer buzz requires substantial marketing support. Consumer buzz from preceding channels and sales volumes are potential measures.

\subsection{Impact of platform-related contingencies}

The value contribution of content is further determined by platform-specific contingencies, which affect the decision-making processes of both acquired and nonacquired customers. To predict platform-specific value contributions, which in turn would enable content owners and buyers to negotiate fairly, we suggest testing various platform contingencies: the contractual setting, assortment, customer-specific factors, and competition. Table 4 provides an overview of the contingencies in these four groups and our respective measurement recommendations.

Prior research has investigated the direct impact of platform specifics, customer preferences, and external competition (e.g., Elberse and Eliashberg 2003) on different outcomes, while few studies have addressed the moderating effects between product and platform contingencies. However, DSPs raise novel leverages that can have a substantial impact on their business model and that have not been investigated in the past. In line with classic economic bundling theory (Danaher et al. 2014), we suspect a positive main effect of favorable specifics (e.g., low fee level, no commercials, strong brand families), which should lower the hurdle of signing up for a service and increase the probability of staying, thereby increasing the number of customers (quantity effect). Regarding the interaction of content elements, the ways these specifics affect the magnitude of content contingencies are even more unclear.

\subsubsection{Contractual settings}

Following the ideas that the value of a subscription model is determined by its features (Lancaster 1966) and liabilities produce risk of consumption, different types of subscription models may have an impact on the general perception and risk associated with a platform subscription. Monthly payment models with the chance to cancel the subscription every month will foster a lower level of perceived risk, while 
Table 4 Overview of platform contingencies, dimensions, and measures

\begin{tabular}{|c|c|}
\hline Dimensions & Recommended measures \\
\hline \multicolumn{2}{|l|}{ Contingency I: contractual setting } \\
\hline \multirow[t]{2}{*}{ Subscription model } & $\begin{array}{l}\text { Length in weeks of contracted period } \\
\text { Period specific price }\end{array}$ \\
\hline & $\begin{array}{l}\text { Number of users per subscription } \\
\text { Binary indicator for maximum video resolution (e.g., } \\
\text { Ultra HD) } \\
\text { Binary indicator for countries with usage permission } \\
\text { Maximum number of devices per subscription } \\
\text { Binary indicator for mobile access }\end{array}$ \\
\hline \multicolumn{2}{|l|}{ Contingency II: platform assortment } \\
\hline Brand families and original programming & $\begin{array}{l}\text { Number of brand families } \\
\text { Number of titles per brand family } \\
\text { Number of original titles }\end{array}$ \\
\hline Impact on the structure of the content bundle & $\begin{array}{l}\text { Number of content pieces in assortment (size) } \\
\text { Number of movies per genre (diversification) } \\
\text { Percentage on new releases (turnover) } \\
\text { Number of new releases per period (timing) } \\
\text { Total box office revenues (return) } \\
\text { Total home video revenues (return) } \\
\text { Revenue decrease rate over time (variance of return) }\end{array}$ \\
\hline Related product offerings & $\begin{array}{l}\text { Number of related products and services } \\
\text { Perceived fit to audiovisual content } \\
\text { Number of related products in online shop }\end{array}$ \\
\hline \multicolumn{2}{|l|}{ Contingency III: customer specifics } \\
\hline Economic situation & $\begin{array}{l}\text { Hours of leisure time per day } \\
\text { Household income per month }\end{array}$ \\
\hline Technological infrastructure & $\begin{array}{l}\text { Binary indicator for broadband access } \\
\text { Average amount of data per second transferred }\end{array}$ \\
\hline \multicolumn{2}{|l|}{ Contingency IV: competition } \\
\hline External competitive environment & $\begin{array}{l}\text { Number of competitors in broad/niche positioning } \\
\text { Number of content pieces distributed by competitors } \\
\text { Advertising budget of competitors } \\
\text { Number of original titles in assortment } \\
\text { Average subscription fee of competitors } \\
\text { Average contraction time of competitors } \\
\text { Binary indicator for DSP is major studio } \\
\text { Number of theatrical releases per month }\end{array}$ \\
\hline
\end{tabular}

platforms with quarterly or even yearly subscription plans may cause higher levels of perceived risk. We suggest that higher perceived risk requires platforms to list more content which captures customer preferences to overcome consumer anxiety and to convince potential customers to join the platform for a long period. We suggest including either a dichotomous variable that controls for the type of plan (e.g., monthly vs. yearly) or a continuous variable that measures the minimum subscription period in days, weeks, and months.

In addition to the time being locked into a platform, total subscription costs may similarly interact with a content piece's revenue contribution potential. 
Higher subscription costs may be a signal for high-quality content, such that platforms charging higher prices would profit less from introducing high-quality content, as customers already expect high quality, whereas platforms with lower prices will profit more from introducing high-quality content. Therefore, we recommend including the subscription price in the model. To ensure comparability across different subscription models, we suggest dividing the price by the subscription period to end up with monthly costs, for example.

Platforms compete not only in terms of content but also in term of additional service features such as the number of allowed account users, type of geofencing, the number of devices included in a subscription, mobile access, and the resolution of content. To prevent churn and keep customers locked in, platforms that allow more than one user per account may benefit more from adding more diverse content, family content, or less specific and niche content, as multiple users on one account may similarly share heterogeneous preferences. Similarly, the addition of a content piece may attract more attention in the acquisition stage when this content is offered in multiple (e.g., original and local soundtrack) languages or accessible through different devices, including mobile. To account for these possible interactions, we recommend including variables in the measurement model, such as counts for the number of allowed users and devices per account (for other measures, see Table 4).

\subsubsection{Platform assortment}

A platform's assortment and degree of content diversification may have divergent implications. As DSPs offer a bundle of content, each new content affects the bundle structure (Geng et al. 2005; Stigler 1963). Releasing new content on the DSP increases the size of the bundle, which removes individual preference heterogeneity through diversification. However, while DSPs with a broad positioning benefit from content that increases the level of diversification, niche and special interest platforms generate value with a high degree of content focused on a specific segment of consumers. Content that has a poor fit with the existing programming lineup might diversify the portfolio and attract new customers with different tastes as well as retain customers through more variety. Table 4 lists a wide range of possible variables such as the number of content pieces per genre, the number of franchises, and the percentage of new releases per quarter. Similarly, the attractiveness of bundling for the service operator increases with slowly decreasing utility correlations among the content pieces (Geng et al. 2005).

The content value increases with higher levels of brand equity, as shown by the prominent examples of the Star Wars saga and the Marvel heroes. Adding a new item to an existing brand family in the assortment generates a reciprocal spillover effect by increasing the value of the new content piece and the other content dedicated to the brand family (Hennig-Thurau et al. 2009). Similarly, a good fit with existing brand families might serve as a quality indicator (e.g., Disney, Netflix Originals) and initiate spillovers to other content dedicated to the brand family. Further, brand families might increase user engagement and thereby foster crosssales (e.g., Disney for kids). 
In addition, a focused portfolio might increase advertising effectiveness, as it allows very specific commercials (e.g., DAZN might show commercials of manufacturers of sports equipment) to be shown. Despite the annoying and disruptive effect of consumption interruptions, there might be specific content that is more suitable to such interruptions than other types. Offering related products might be especially suitable for live (sporting) events (e.g., offering fan equipment) and blockbuster movies such as The Lord of the Rings (e.g., merchandise tie-ins). To account for assortment policy and control for possible interactions, we suggest including variables that measure assortment by taking the share of the genres (e.g., number of action movies to total number of movies) in a platform. As Table 4 shows, the content's brand equity could be measured with the help of variables such as the number of brand families, content pieces dedicated to each brand family, and the perceived level of integration in the brand family.

\subsubsection{Customer-specific factors}

Customers face differences in economic situation and technological infrastructure. These contingencies affect consumer behavior (e.g., Kübler et al. 2020; Smith and Telang 2010). However, how these contingencies affect revenue streams is unclear. Most obviously, a high household income and a high number of hours of leisure time increase subscription revenue through acquisition and retention. Customers with a high household income might face quite a low hurdle in signing up or staying with a service, while customers with a high number of hours of leisure time might have a high activity level, resulting in a low likelihood of canceling the service. In addition, a high activity level leads to higher advertising revenues. Finally, we assume that a high household income and a high activity level also result in increased cross-sales. Regarding technological infrastructure, we assume a strong link to subscription revenues through acquisition, as a high level of internet penetration and bandwidth is the fundamental requirement for the growth of video streaming services, which offer content via the internet. Content valuation models may therefore also include fixed-effect variables accounting for different economic (e.g., gross domestic product, Gini, average hours of leisure time in a country/region) or cultural (e.g., Hofstede or Schwartz) settings of different platforms.

Further, platforms may build a homogeneous (e.g., Disney +) customer base with rather similar preferences or a heterogeneous customer base (e.g., Amazon Prime) with multiple and varying interests. Depending on the preference structure of the customer base, the addition of specific content pieces may differently contribute to the three revenue streams, as also stressed by the classic bundling literature (e.g., Danaher et al. 2014). Each platform may thus have its unique customer base with a specific preference structure that reacts differently to content additions. To account for this, an empirical model could include the average consumption share of genres or the average time watched per genre. 


\subsubsection{Competition}

Strong competitive film and media offerings of other platforms might decrease competitors' acquisition likelihood and increase the likelihood of the cancelation of one or more of their services by consumers. In terms of content interaction, strong competition might decrease the value provided by a content piece when other platforms provide a cheaper and more attractive service. As Table 4 shows, competition can be measured by variables such as the number of competitors in the market, competitors' number of unique titles, competitors' number of customers, the customer or market share of a platform, or the share of voice in terms of earned social media content.

\section{Conclusion}

In this article, we aimed to develop a conceptual framework that facilitates the valuation of content in DSPs. We show that the value of a platform's content is composed of up to three revenue streams related to the platform's business model and differentiation strategy. We first distinguish between the acquisition effect (content causes users to start to use/subscribe to the platform) and the retention effect (content causes users to stay engaged with the platform) of content. Second, we argue that content can trigger cross-sales within the platform, or by attracting consumers to the platform, more eyeballs can be sold to advertisers. Third, we account for direct value contribution (leading to a subscription or the prevention of a churn) and indirect value contribution (by supporting the impact of other content alongside the customer journey).

Each business model provides a different content strategy to generate the highest value for the DSP, whether scaling a niche, offering an exclusive premium DSP, promoting an online shop, or even using a pure subscription-based strategy, just to name a few. Thus, controlling the business model and content is essential to generate the maximum value from content and gain a competitive advantage.

In the era of big data, datafication plays an important role in content strategy. Platforms may use this information for first- and third-party advertising and crossselling but also for making strategic decisions about which content to produce or license. The fit between content and a DSP is essential. Thus, especially data-driven content product becomes highly relevant. In addition, data help improve recommendation systems and other automated services on a DSP. However, access to data is a critical resource that creates a competitive advantage (also reflected in the willingness of DSPs to share data with other parties). Thus, distributors that license their content to DSPs should integrate this issue into their strategies (e.g., in negotiations with DSPs).

The sequential distribution schedules for audiovisual content ensured that producers and distributors broke even. However, the emergence and prevalence of DSPs are eroding these patterns. For example, rumors of simultaneous theater and DSP releases indicate the move toward new exploitation schemes. However, corporate reactions to these market changes can also culminate in separation strategies, as shown by Disney + . This article takes a step toward determining 
Table 5 Overview of potential research avenues

\begin{tabular}{|c|c|}
\hline Research avenue & Focus and specific research questions \\
\hline $\begin{array}{l}\text { Determining the } \\
\text { incremental value of } \\
\text { content }\end{array}$ & $\begin{array}{l}\text { Future research should address the ROI, } \\
\text { attribution, and customer journey litera- } \\
\text { ture, identifying performance indicators } \\
\text { and attribution metrics that depict the } \\
\text { content direct and indirect value contri- } \\
\text { bution to platform's cash flows } \\
\text { R1: Which performance indicators and } \\
\text { related metrics are appropriate to capture } \\
\text { the DSP success, and, how are these } \\
\text { metrics interrelated? } \\
\text { R2: For the acquisition funnel, how } \\
\text { does a content piece affect awareness, } \\
\text { consideration, and choice to register for } \\
\text { a platform? } \\
\text { R3: For the usage funnel, how does a } \\
\text { content piece affect the decision process } \\
\text { of staying with a platform, and which } \\
\text { attribution measures can predict the } \\
\text { churn from the service? } \\
\text { R4: For cross-sales and advertising, how } \\
\text { does a content piece affect direct and } \\
\text { indirect effectiveness of advertising and } \\
\text { cross-sales, and which attribution meas- } \\
\text { ures predict cross-sales and advertising } \\
\text { success? }\end{array}$ \\
\hline
\end{tabular}

The impact of content and platform contingencies
The value contribution of content varies with content and platform contingencies. Future research should address the cultural economics and marketing-mix literature to provide empirical elasticities of a content contingency's influence on different kinds of DSP value. Future research should also address the literature on platforms, bundling, customer preferences, and competitive dynamics to provide empirical elasticities of a platform contingency's influence on different kinds of DSP value

R5: To what extent does the impact of contingencies identified in prior research differ in the DSP context, and which contingencies are unique to DSPs?

R6: Does the impact of contingencies differ between non-customers' and customers' journey, and how do contingencies affect cross-sales and advertising effectiveness?

R7: How do various content and platform contingencies moderate the impact of others, respectively?

R8: How do content and platform contingencies interact with each other? 
how audiovisual content is valued by digital platforms and which factors affect the value of a single piece of content in a platform's specific bundle.

However, our discussion raises important questions which future research could address. Table 5 provides an overview of potential research questions grouped into two research avenues. First, to be able to measure the value of a content piece or its particular contingencies, research needs to address the ROI, attribution, and customer journey literature and determine attributional metrics and performance indicators that capture the direct and indirect value contribution to a platform's cash flow. Second, the value contribution of content varies with content and platform contingencies. Research needs to determine these contingencies and provide empirical measures of their influence on different kinds of DSP value.

Acknowledgements We thank the editors of this special issue as well as the anonymous reviewers for their thoughtful, constructive, and very helpful feedback. In addition, we thank the participants of the Mallen 2018 conference (Potsdam, Germany) and extend our gratitude to Paul Crosby, Rick Gretz, Yong Liu, Christian Peukert, and Michel Clement for their valuable feedback on previous versions of this manuscript. We also thank Stefan Bauer for providing critical industry perspectives and insights.

Funding Open Access funding provided by Projekt DEAL.

Open Access This article is licensed under a Creative Commons Attribution 4.0 International License, which permits use, sharing, adaptation, distribution and reproduction in any medium or format, as long as you give appropriate credit to the original author(s) and the source, provide a link to the Creative Commons licence, and indicate if changes were made. The images or other third party material in this article are included in the article's Creative Commons licence, unless indicated otherwise in a credit line to the material. If material is not included in the article's Creative Commons licence and your intended use is not permitted by statutory regulation or exceeds the permitted use, you will need to obtain permission directly from the copyright holder. To view a copy of this licence, visit http://creativecommons.org/licen ses/by/4.0/.

\section{References}

Adams, W. J., \& Yellen, J. L. (1976). Commodity bundling and the burden of monopoly. Quarterly Journal of Economics, 90(3), 475-498.

Armstrong, M. (1996). Multiproduct nonlinear pricing. Econometrica: Journal of the Econometric Society, 64(1), 51-75.

Armstrong, M., \& Vickers, J. (2010). Competitive non-linear pricing and bundling. Review of Economic Studies, 77(1), 30-60.

Basuroy, S., Chatterjee, S., \& Ravid, S. A. (2003). How critical are critical reviews? The box office effects of film critics, star power, and budgets. Journal of Marketing, 67(4), 103-117.

Berger, P. D., \& Nasr, N. I. (1998). Customer lifetime value: Marketing models and applications. Journal of Interactive Marketing, 12(1), 17-30.

Bohnenkamp, B., Knapp, A. K., Hennig-Thurau, T., \& Schauerte, R. (2015). When does it make sense to do it again? An empirical investigation of contingency factors of movie remakes. Journal of Cultural Economics, 39(1), 15-41.

Bruce, N. I., Foutz, N. Z., \& Kolsarici, C. (2012). Dynamic effectiveness of advertising and word of mouth in sequential distribution of new products. Journal of Marketing Research, 49(4), 469-486.

Churchill, G. A., Jr., \& Surprenant, C. (1982). An investigation into the determinants of customer satisfaction. Journal of Marketing Research, 19(4), 491-504. 
Clark, T. (2018). New data shows Netflix's number of movies has gone down by thousands of titles since 2010-But its TV catalog size has soared. Business Insider. Retrieved November 19, 2019 from https://www.businessinsider.de/netflix-movie-catalog-size-has-gone-down-since $-2010-2018-2$ ? $\mathrm{r}=\mathrm{US} \& \mathrm{IR}=\mathrm{T}$.

Clark, T. (2019). 13 of the biggest box-office flops of 2019 so far. Business Insider. Retrieved November 19, 2019 from https://www.businessinsider.de/biggest-box-office-flops-2019-hellboy-the-beach -bum-tolkien-2019-5?r=US\&IR=T.

Conchar, M. P., Crask, M. R., \& Zinkhan, G. M. (2005). Market valuation models of the effect of advertising and promotional spending: A review and meta-analysis. Journal of the Academy of Marketing Science, 33(4), 445-460.

Danaher, B., Dhanasobhon, S., Smith, M. D., \& Telang, R. (2010). Converting pirates without cannibalizing purchasers: The impact of digital distribution on physical sales and internet piracy. Marketing Science, 29(6), 1138-1151.

Danaher, B., Huang, Y., Smith, M. D., \& Telang, R. (2014). An empirical analysis of digital music bundling strategies. Management Science, 60(6), 1413-1433.

Dastin, J. (2018). Exclusive: Amazon's internal numbers on Prime Video, revealed. Reuters. Retrieved November 19, 2019 from https://www.reuters.com/article/us-amazon-com-ratings-exclusive/exclu sive-amazons-internal-numbers-on-prime-video-revealed-idUSKCN1GR0FX.

De Haan, E., Wiesel, T., \& Pauwels, K. (2016). The effectiveness of different forms of online advertising for purchase conversion in a multiple-channel attribution framework. International Journal of Research in Marketing, 33(3), 491-507.

Deloitte. (2018). Future scenarios for the TV and video industry by 2030. Deloitte. Retrieved November 19, 2019 from https://www2.deloitte.com/de/de/pages/technology-media-and-telecommunications/ articles/future-of-tv-video.html.

Edelman, D., \& Banfi, F. (2014). The funnel is dead. Long live the consumer decision journey. Retrieved November 19, 2019 from https://www.mckinsey.com/business-functions/marketing-and-sales/ourinsights/the-funnel-is-dead-long-live-the-consumer-decision-journey.

Elberse, A. (2007). The power of stars: Do star actors drive the success of movies? Journal of Marketing, 71(4), 102-120.

Elberse, A. (2010). Bye-bye bundles: The unbundling of music in digital channels. Journal of Marketing, 74(3), 107-123.

Elberse, A., \& Eliashberg, J. (2003). Demand and supply dynamics for sequentially released products in international markets: The case of motion pictures. Marketing Science, 22(3), 329-354.

Eliashberg, J., Elberse, A., \& Leenders, M. A. (2006). The motion picture industry: Critical issues in practice, current research, and new research directions. Marketing Science, 25(6), 638-661.

Fang, H., \& Norman, P. (2003). An efficiency rationale for bundling of public goods. Cowles Foundation Discussion Paper No. 1441; SSRI Working Paper No. 2003-19.

Farris, P. W., Hanssens, D. H., Lenskold, J. D., \& Reibstein, D. J. (2015). Marketing return on investment: Seeking clarity for concept and measurement. Applied Marketing Analytics, 1(3), 267-282.

Fornell, C. (1992). A national customer satisfaction barometer: The Swedish experience. Journal of Marketing, 56(1), 6-21.

Gemser, G., Leenders, M. A., \& Wijnberg, N. M. (2008). Why some awards are more effective signals of quality than others: A study of movie awards. Journal of Management, 34(1), 25-54.

Geng, X., Stinchcombe, M. B., \& Whinston, A. B. (2005). Bundling information goods of decreasing value. Management Science, 51(4), 662-667.

Goldberg, L. (2019). 'The Office' to leave Netflix in 2020, stream exclusively on NBC Universal's forthcoming service. The Hollywood Reporter. Retrieved November 19, 2019 from https://www.holly woodreporter.com/live-feed/office-leave-netflix-2020-stream-exclusively-nbcuniversals-forthcomin g-service-1220954.

Gong, J., Smith, M. D., \& Telang, R. (2015). Substitution or promotion? The impact of price discounts on cross-channel sales of digital movies. Journal of Retailing, 91(2), 343-357.

Hadida, A. L. (2009). Motion picture performance: A review and research agenda. International Journal of Management Reviews, 11(3), 297-335.

Hall, E. (2014). Netflix braves cultural barriers for European expansion. AdAge. Retrieved November 19, 2019 from https://adage.com/article/global-news/netflix-braves-cultural-barriers-european-expan sion/295035. 
Hamilton, R., Thompson, D., Bone, S., Chaplin, L. N., Griskevicius, V., Goldsmith, K., et al. (2019). The effects of scarcity on consumer decision journeys. Journal of the Academy of Marketing Science, 47(3), 532-550.

Hanssens, D. M., Pauwels, K. H., Srinivasan, S., Vanhuele, M., \& Yildirim, G. (2014). Consumer attitude metrics for guiding marketing mix decisions. Marketing Science, 33(4), 534-550.

Hauser, J. R., \& Wernerfelt, B. (1990). An evaluation cost model of consideration sets. Journal of Consumer Research, 16(4), 393-408.

Hennig-Thurau, T., Henning, V., Sattler, H., Eggers, F., \& Houston, M. B. (2007). The last picture show? Timing and order of movie distribution channels. Journal of Marketing, 71(4), 63-83.

Hennig-Thurau, T., \& Houston, M. B. (2018). Entertainment science: Data analytics and practical theory for movies, games, books, and music. Cham: Springer.

Hennig-Thurau, T., Houston, M. B., \& Heitjans, T. (2009). Conceptualizing and measuring the monetary value of brand extensions: The case of motion pictures. Journal of Marketing, 73(6), 167-183.

Hennig-Thurau, T., Schauerte, R., Herborg, N., \& Wiechmann, D. (2019). Quo Vadis, Deutsche Medien? Zur Zukunft deutscher Fernsehanbieter in digitalen Streaming-Zeiten. Roland Berger. Retrieved November 19, 2019 from https://www.rolandberger.com/publications/publication_pdf/roland_berge r_tv_der_zukunft.pdf.

Hofmann-Stölting, C., Clement, M., Wu, S., \& Albers, S. (2018). Sales forecasting of new entertainment media products. Journal of Media Economics, 30(3), 143-171.

Holbrook, M. B., \& Hirschman, E. C. (1982). The experiential aspects of consumption: Consumer fantasies, feelings, and fun. Journal of Consumer Research, 9(2), 132-140.

Houston, M. B., Kupfer, A. K., Hennig-Thurau, T., \& Spann, M. (2018). Pre-release consumer buzz. Journal of the Academy of Marketing Science, 46(2), 338-360.

John, K., Ravid, S. A., \& Sunder, J. (2017). Managerial ability and success: Evidence from the career paths of film directors. Journal of Corporate Finance, 44, 425-439.

Joshi, A., \& Mao, H. (2012). Adapting to succeed? Leveraging the brand equity of best sellers to succeed at the box office. Journal of the Academy of Marketing Science, 40(4), 558-571.

Kannan, P. K., Reinartz, W., \& Verhoef, P. C. (2016). The path to purchase and attribution modeling: Introduction to special section. International Journal of Research in Marketing, 33(3), 449-456.

Keller, K. L. (1993). Conceptualizing, measuring, and managing customer-based brand equity. Journal of Marketing, 57(1), 1-22.

Kübler, R. V., Colicev, A., \& Pauwels, K. H. (2020). Social media's impact on the consumer mindset: When to use which sentiment extraction tool? Journal of Interactive Marketing, 50, 136-155.

Lancaster, K. J. (1966). A new approach to consumer theory. Journal of Political Economy, 74(2), $132-157$.

Lee, E. (2018). Netflix will keep 'Friends' through next year in a $\$ 100$ million agreement. The New York Times. Retrieved November 19, 2019 from https://www.nytimes.com/2018/12/04/business/media/ netflix-friends.html.

Lemon, K. N., \& Verhoef, P. C. (2016). Understanding customer experience throughout the customer journey. Journal of Marketing, 80(6), 69-96.

Liu, Y. (2006). Word of mouth for movies: Its dynamics and impact on box office revenue. Journal of Marketing, 70(3), 74-89.

Long, J. B. (1984). Comments on "Gaussian Demand and Commodity Bundling". Journal of Business, 57(1), S235-S246.

McAfee, R. P., McMillan, J., \& Whinston, M. D. (1989). Multiproduct monopoly, commodity bundling, and correlation of values. Quarterly Journal of Economics, 104(2), 371-383.

Morris, D. (2016). Here's how "House of Cards" viewership stacks up against the offline competition (maybe). Fortune. Retrieved November 19, 2019 from https://fortune.com/2016/03/05/house-ofcards-viewership/.

Nalebuff, B. (2004). Bundling as an entry barrier. Quarterly Journal of Economics, 119(1), 159-187.

Netflix. (2019). Netflix annual report. Retrieved November 19, 2019 from https://s22.q4cdn.com/95985 3165/files/doc_financials/annual_reports/2018/Form-10K_Q418_Filed.pdf.

Palia, D., Ravid, S. A., \& Reisel, N. (2008). Choosing to cofinance: Analysis of project-specific alliances in the movie industry. Review of Financial Studies, 21(2), 483-511.

Payne, A., \& Frow, P. (2005). A strategic framework for customer relationship management. Journal of Marketing, 69(4), 167-176.

Peterson, R. A., \& Wilson, R. W. (1992). Measuring customer satisfaction: Fact and artifact. Journal of the Academy of Marketing Science, 20(1), 61-71. 
PwC. (2019). Perspectives from the Global Entertainment \& Media Outlook 2019-2023. Getting personal: Putting the me in entertainment and media. Retrieved November 19, 2019 from https://www.pwc.com/ gx/en/entertainment-media/outlook-2019/entertainment-and-media-outlook-perspectives-2019-2023.pdf.

Raghunath, A. (2019). Disney's streaming service will launch in November. Market Realist. Retrieved November 19, 2019 from https://marketrealist.com/2019/06/disneys-streaming-service-will-launc h-in-november/.

Ravid, S. Abraham. (1999). Information, blockbusters and stars? A study of the film industry. The Journal of Business, 72(4), 463-492.

Rinallo, D., \& Basuroy, S. (2009). Does advertising spending influence media coverage of the advertiser? Journal of Marketing, 73(6), 33-46.

Rust, R. T., Lemon, K. N., \& Zeithaml, V. A. (2004). Return on marketing: Using customer equity to focus marketing strategy. Journal of Marketing, 68(1), 109-127.

Sherman, A. (2019a). Disney won't hurt Netflix by stealing subscribers-But it will make it harder for Netflix to raise prices. CNBC. Retrieved November 19, 2019 from https://www.cnbc. com/2019/08/07/disney-strategy-could-limit-netflix-pricing-power-hurting-long-term.html.

Sherman, A. (2019b). How the epic "Lord of the Rings" deal explains Amazon's slow-burning media strategy. CNBC. Retrieved November 19, 2019 from https://www.cnbc.com/2019/03/08/amazo n-prime-video-feature.html.

Simonson, I. (2005). Determinants of customers' responses to customized offers: Conceptual framework and research propositions. Journal of Marketing, 69(1), 32-45.

Smith, M. D., \& Telang, R. (2010). Piracy or promotion? The impact of broadband Internet penetration on DVD sales. Information Economics and Policy, 22(4), 289-298.

Smith, M. D., \& Telang, R. (2019). Netflix and the economics of bundling. Harvard Business Review. Retrieved June 10, 2020 from https://hbr.org/2019/02/netflix-and-the-economics-of-bundling.

Spangler, T. (2019). Netflix spent $\$ 12$ billion on content in 2018. Analysts expect that to grow to $\$ 15$ billion this year. Variety. Retrieved November 19, 2019 from https://variety.com/2019/digital/news/ netflix-content-spending-2019-15-billion-1203112090/.

Srinivasan, S., \& Hanssens, D. M. (2009). Marketing and firm value: Metrics, methods, findings, and future directions. Journal of Marketing Research, 46(3), 293-312.

Srinivasan, S., Rutz, O. J., \& Pauwels, K. (2016). Paths to and off purchase: Quantifying the impact of traditional marketing and online consumer activity. Journal of the Academy of Marketing Science, 44(4), 440-453.

Statista. (2019). Statista digital market outlook. Retrieved November 19, 2019 from https://www.statista. com/statistics/459430/digital-video-user-penetration-type-digital-market-outlook-usa/.

Stigler, G. J. (1963). United States v. Loew's Inc.: A note on block-booking. The Supreme Court Review, $1963,152-157$.

Stigler, G. J. (1968). The organization of industry. Chicago: University of Chicago Press.

Stremersch, S., \& Tellis, G. J. (2002). Strategic bundling of products and prices: A new synthesis for marketing. Journal of Marketing, 66(1), 55-72.

Venkatesan, R., \& Kumar, V. (2004). A customer lifetime value framework for customer selection and resource allocation strategy. Journal of Marketing, 68(4), 106-125.

Verhoef, P. C. (2003). Understanding the effect of customer relationship management efforts on customer retention and customer share development. Journal of Marketing, 67(4), 30-45.

Wang, C. (2018). More than half of U.S. homes now subscribe to a streaming service, spending \$2.1 billion a month. CNBC. Retrieved November 19, 2019 from https://www.cnbc.com/2018/03/19/strea ming-services-americans-spend-2-point-1-billion-a-month-in-55-percent-homes.html.

Wernerfelt, B. (1984). A resource-based view of the firm. Strategic Management Journal, 5(2), 171-180.

Wertz, J. (2018). Don't spend 5 times more attracting new customers, nurture the existing ones. Forbes. Retrieved November 19, 2019 from https://www.forbes.com/sites/jiawertz/2018/09/12/dont-spend -5-times-more-attracting-new-customers-nurture-the-existing-ones/.

Wiesel, T., Pauwels, K., \& Arts, J. (2011). Marketing's profit impact: Quantifying online and off-line funnel progression. Marketing Science, 30(4), 565-756.

Winer, R. S. (2001). A framework for customer relationship management. California Management Review, 43(4), 89-105.

Zhou, J. (2017). Competitive bundling. Econometrica, 85(1), 145-172.

Publisher's Note Springer Nature remains neutral with regard to jurisdictional claims in published maps and institutional affiliations. 


\section{Affiliations}

\section{Raoul Kübler ${ }^{1} \cdot$ Rouven Seifert ${ }^{2} \cdot$ Michael Kandziora ${ }^{2}$}

Rouven Seifert

rouven.seifert@uni-hamburg.de

Michael Kandziora

michael.kandziora@uni-hamburg.de

1 Marketing Center Münster, University of Münster, Am Stadtgraben 13-15, 48143 Münster, Germany

2 Institute of Marketing, University of Hamburg, Moorweidenstraße 18, 20148 Hamburg, Germany 